\title{
Genetic Characterization of Brain Metastases in the Era of Targeted Therapy
}

\author{
Catherine H. Han ${ }^{1,2}$ and Priscilla K. Brastianos ${ }^{1 *}$ \\ 'Departments of Neurology and Radiation Oncology, Division of Hematology/Oncology, Massachusetts General Hospital \\ Cancer Center, Harvard Medical School, Boston, MA, United States, ${ }^{2}$ Auckland Cancer Society Research Centre, Faculty of \\ Medical and Health Sciences, School of Medical Sciences, University of Auckland, Auckland, New Zealand
}

\section{OPEN ACCESS}

Edited by:

David D. Eisenstat,

University of Alberta, Canada

Reviewed by:

Stephen Yip,

University of British Columbia,

Canada

Craig Horbinski,

Northwestern University, United

States

Thomas Klonisch

University of Manitoba, Canada

*Correspondence:

Priscilla K. Brastianos pbrastianos@mgh.harvard.edu

Specialty section: This article was submitted to Neuro-Oncology and

Neurosurgical Oncology,

a section of the journal

Frontiers in Oncology

Received: 27 July 2017 Accepted: 07 September 2017 Published: 25 September 2017

Citation:

Han CH and Brastianos PK (2017)

Genetic Characterization of

Brain Metastases in the Era of Targeted Therapy.

Front. Oncol. 7:230.

doi: 10.3389/fonc.2017.00230
In the current era of molecularly targeted therapies and precision medicine, choice of cancer treatment has been increasingly tailored according to the molecular or genomic characterization of the cancer the individual has. Previously, the clinical observation of inadequate control of brain metastases was widely attributed to a lack of central nervous system (CNS) penetration of the anticancer drugs. However, more recent data have suggested that there are genetic explanations for such observations. Genomic analyses of brain metastases and matching primary tumor and other extracranial metastases have revealed that brain metastases can harbor potentially actionable driver mutations that are unique to them. Identification of genomic alterations specific to brain metastases and targeted therapies against these mutations represent an important research area to potentially improve survival outcomes for patients who develop brain metastases. Novel approaches in genomic testing such as that using cell-free circulating tumor DNA (ctDNA) in the cerebrospinal fluid (CSF) facilitate advancing our understanding of the genomics of brain metastases, which is critical for precision medicine. CSF-derived ctDNA sequencing may be particularly useful in patients who are unfit for surgical resection or have multiple brain metastases, which can harbor mutations that are distinct from their primary tumors. Compared to the traditional chemotherapeutics, novel targeted agents appear to be more effective in controlling the CNS disease with better safety profiles. Several brain metastases-dedicated trials of various targeted therapies are currently underway to address the role of these agents in the treatment of CNS disease. This review focuses on recent advances in genomic profiling of brain metastases and current knowledge of targeted therapies in the management of brain metastases from cancers of the breast, lung, colorectum, kidneys, and ovaries as well as melanoma.

Keywords: brain metastases, genomics, targeted therapy, sequencing, cancer heterogeneity

\section{INTRODUCTION}

Brain metastases are the most common central nervous system (CNS) tumors in adults but represent an unmet need in current oncologic practice. The reported incidence of brain metastases is $9-17 \%$; however, the true incidence in the current era of modern cancer therapies is thought to be higher (1). The incidence of brain metastases is rising due, in part, to improved diagnostic techniques and 
increased patient survival through advanced systemic treatment approaches. Some types of cancers have greater tropism of metastasizing to the brain with most common cancers being lung cancer (39-56\%), breast cancer (13-30\%), melanoma (6-11\%), gastrointestinal cancers (3-8\%), and renal cell carcinoma (2-4\%) (2). The underlying mechanisms of this organotropism toward specific secondary sites remain poorly understood.

Prognosis remains poor with a median survival ranging from 3 to 27 months after developing brain metastases (3). Treatment options are limited and usually involve multimodality approaches that include radiotherapy, surgery, and sometimes systemic therapy, depending on number of lesions, location, and primary tumor type. Historically, patients with brain metastases were uniformly treated with whole-brain radiotherapy, especially if multiple lesions are present, or surgical resection followed by radiotherapy for a solitary or large symptomatic lesion. More recently, stereotactic radiosurgery has been increasingly used for smaller lesions $(<3 \mathrm{~cm})$ in oligometastatic disease, which is commonly defined as up to four brain metastases. CNS-directed systemic treatment options are limited, and patients with brain metastases are commonly excluded from clinical trials, including those investigating novel targeted therapies. Differential responses to systemic treatments between brain metastases and extracranial disease are often observed, particularly with the traditional chemotherapy agents, where systemic disease is adequately controlled while brain disease progresses. This is at least partly explained by inadequate blood-brain barrier (BBB) penetration by systemic therapies (4). Although the $\mathrm{BBB}$ is frequently compromised by brain metastases as shown by brain imaging contrast enhancement, the residual BBB permeability limits drug delivery to subtherapeutic concentrations in brain metastases compared with extracranial tumors. With molecularly targeted therapies, there has been improved control of both intracranial and extracranial metastases. In the past decade, significant efforts have been made to characterize the genetic drivers in brain metastases using modern sequencing techniques. Better understanding of the genomic complexity and heterogeneity of brain metastases will lead to improved treatment strategies and research directions. This review focuses on recent advances in genomic profiling of brain metastases and current knowledge of targeted therapies in the management of brain metastases from cancers of the breast, lung, colorectum, kidneys, and ovaries as well as melanoma.

\section{GENETIC HETEROGENEITY OF CANCER}

Intratumoral heterogeneity within the primary tumor was shown in a multiregion spatial genetic analysis of four metastatic renal cell carcinoma (5). Genetic heterogeneity between primary and secondary tumors in the same patient was also shown in a study comparing the genetic profiling of 15 primary colorectal cancer and matched liver metastases (6). Similarly, genetic heterogeneity between brain metastases and their corresponding primary tumors was shown recently in a genomic analysis of matched brain metastases, primary tumors, and normal tissue in 86 patients (7). This study demonstrated that brain metastases harbor distinctive potentially actionable mutations not detected in paired primary tumors in $53 \%$ of the cases. This finding suggests that this genomic heterogeneity or divergent evolution of brain metastases from primary tumors may also contribute to the disparities in intracranial and extracranial disease response to systemic therapies, which were previously thought to be solely due to the inadequate $\mathrm{BBB}$ penetration of systemic drugs. In the same study, it was found that alterations associated with sensitivity to cyclin-dependent kinase (CDK) inhibitors were common in brain metastases (7). These include CDKN2A loss and $C D K 4 / 6$ amplifications. Alterations in the PI3K/AKT/mTOR pathway were also common as previously reported by others (8-10). Interestingly, brain metastases from different intracranial sites in the same patient shared nearly all of the potentially actionable driver mutations, suggesting that brain metastases are homogeneous within an individual (7). Prospective clinical trials using targeted therapies that cross the $\mathrm{BBB}$ are required to demonstrate that these potentially actionable mutations found in brain metastasis samples are indeed targetable.

\section{GENOMIC PROFILING OF BRAIN METASTASES}

In the current era of molecularly targeted therapies and precision medicine, choice of cancer treatment has been increasingly tailored according to the molecular or genomic characterization of the cancer the individual has. Identification of genomic alterations specific to brain metastases and targeted therapies against these mutations represent an important research area to improve survival outcomes for patients who develop brain metastases. Given spatial and temporal intratumoral heterogeneity within the same patient, repeated biopsies are often necessary to adequately characterize the somatic genetic alterations in human cancers. Genomic profiling of brain metastases poses a particular challenge as obtaining tissue samples of brain metastases is invasive and often difficult, especially in patients who are poor candidates for brain resections or have tumors in inaccessible sites. In addition, regional lymph node and other distal extracranial metastasis samples are not reliable surrogates for detecting these mutations present in brain metastases (7).

There has been great interest in developing alternative methods of genomic profiling of cancer that are clinically practical and non-invasive. Information collected by these techniques not only help refine systemic treatment decisions but also monitor response to treatment and identify emergent drug-resistant mutations by tracking the evolution of cancer genome to guide further therapy. For example, analysis of circulating tumor DNA (ctDNA) in plasma has been shown to be useful not only in characterizing cancers but also in monitoring disease response to therapy (11-13). However, it was recently shown that tumor DNA was either absent or present in a very little amount in the plasma of patients with primary brain tumors or brain metastases with no or little extracranial disease from solid tumors (12). In the same study, mutations that were present only in the brain metastases and not in the extracranial tumors were more represented in the cell-free ctDNA from the cerebrospinal fluid (CSF) compared to plasma. As seen with plasma ctDNA in previous studies, CSF ctDNA was also observed to change 
throughout treatments (12). Mutant allelic frequency of CSF ctDNA decreased with tumor response to treatments and increased with progression.

Brain metastases can harbor drug-resistant mutations that result in restoration of signaling downstream of the target kinase, activation of an alternative signaling pathway, or alteration in the drug activating site (14). And these mutations may not be present in the primary tumor or extracranial metastases (7), therefore, genotyping primary tumor or other extracranial disease alone can miss actionable oncogenic driver mutations and targeted therapy opportunities for brain metastases. Routine brain biopsies are invasive with associated risks and may not be feasible in many patients with brain metastases. CSF ctDNA analysis may provide the ability to identify the drug-resistance mechanisms in patients who progressed in the CNS after initial response on targeted therapy without invasive procedures like a brain biopsy. In a recent study, CSF as a source of ctDNA was evaluated by sequencing 341 cancer-associated genes in cell-free DNA isolated from the CSF of 53 patients with brain metastases of solid tumors or primary brain tumors (14). Mutations, which are known to cause drug resistance to oncogenic kinases, were identified in 4 of 12 patients who progressed in the brain whilst on such therapy. Although this needs to be verified in a larger cohort of patients, these findings suggest that CSF ctDNA may be a useful biomarker that facilitates genome-directed treatments to target brain metastases and for monitoring CNS disease on treatment or during surveillance. Moving forward, more studies evaluating ctDNA extracted from CSF should be carried out using next-generation sequencing techniques that are capable of detection all classes of mutations including base substitutions/insertions/deletions, gene fusions, and gene copy number alterations. The fraction of cell-free ctDNA in CSF is higher than in plasma due to the relative absence of background normal DNA in CSF. This allows the detection of somatic mutations even with modest sequence coverage, whereas plasma cell-free ctDNA sequencing requires very deep sequence coverage to achieve sufficient sensitivity for detecting mutations occurring at low allele frequencies. CSF ctDNA analysis appears promising, and there are ongoing studies prospectively evaluating CSF ctDNA as a surrogate for brain metastasis biopsy sample. Furthermore, the use of additional circulating biomarkers, such as exosomes, will need to be prospectively explored.

\section{NON-SMALL CELL LUNG CANCER (NSCLC)}

Non-small cell lung cancer is the most common type of lung cancer, accounting for approximately $85 \%$ of all lung cancer cases (15). NSCLC, adenocarcinoma subtype in particular, is the most common cancer to metastasize to the brain (1). The risk of developing brain metastases during the course of disease in patients with treated stage III NSCLC is approximately $30-50 \%$ (15). Even in patients with surgically treated early stage (stage I-II) NSCLC, the 5-year actuarial risk of developing brain metastases is reported to be around $10 \%$ with the brain being the sole site of failure in $43 \%$ of these patients $(15,16)$. A large retrospective study of 975 patients with stage I-II NSCLC identified younger age, larger tumor size, lymphovascular space invasion, and hilar lymph node involvement to be associated with an increase in the risk of brain metastases in this population (15). Prognosis remains poor even with a multimodality treatment approach of brain metastases. Reported 1-year mortality rate after developing brain metastases ranges from 81 to $90 \%$ depending on the initial clinical stage of lung cancer (16). Discovery of NSCLC oncogenic driver mutations and molecularly targeted therapies have significantly improved survivals in the subset of patients with metastatic NSCLC harboring these targetable genomic aberrations.

\section{Epidermal Growth Factor Receptor (EGFR) Mutations}

An activating EGFR mutation is present in approximately $10-15 \%$ of Caucasians and $40 \%$ of East-Asian NSCLC patients (2). When the EGFR status was evaluated in paired brain metastasis and corresponding primary lung tumor samples, discordance rates up to $33 \%$ were observed (2). In a recent retrospective, populationbased study, there was a higher cumulative incidence of brain metastases in patients with EGFR-mutant NSCLC compared to those with EGFR wild type (39.2 versus $28.2 \%$ ) (17). EGFR mutations render these tumors sensitive to EGFR tyrosine kinase inhibitors (TKIs) resulting in significantly improved survival outcomes. Several phase III randomized trials compared the efficacy of first-generation EGFR TKIs, gefitinib and erlotinib, and an irreversible ErbB family inhibitor, afatinib, to the platinumcontaining combination chemotherapy as first-line treatment in EGFR-mutant NSCLC patients. Progression-free survival (PFS) was significantly longer in the EGFR TKI group compared to the chemotherapy group, with hazard ratios for progression or death ranging from 0.38 to $0.58(18-20)$.

Prospective data on the efficacy of EGFR TKIs in treating brain metastases from NSCLC are limited. However, currently available data suggest that these agents have CNS activity. Post hoc subgroup analyses of combined data from two phase III randomized trials of first-line afatinib in EGFR-mutant NSCLC patients, which allowed patients with asymptomatic brain metastases to enroll, showed survival benefit from treatment with afatinib compared to chemotherapy (21). PFS (8.2 versus 5.4 months) and objective response rate (ORR) (70-75 versus $20-28 \%$ ) were significantly better with afatinib than chemotherapy. Pretreated patients with brain metastases may also benefit from afatinib as suggested by a report of 31 patients, of whom $35 \%$ had an objective response with an overall disease control rate of $66 \%$ (22). Other retrospective and small phase II studies also showed survival benefit from first-generation TKIs in patients with EGFR-mutant NSCLC that had metastasized to the brain (23-26). In these studies, ORR was $58-83 \%$, and median PFS was in the range of 7-15 months.

The majority of patients who had initial response to EGFR TKIs had disease progression due to an acquired resistance within 1-2 years (27). The development of an additional EGFR mutation, EGFR T790M, is responsible for approximately $60 \%$ of this clinically observed acquired resistance (28). A third-generation T790M mutant specific EGFR TKI, osimertinib, has been shown to be highly active in patients who have progressed during prior 
therapy with EGFR TKIs due to T790M mutation (27). Moreover, a recent preclinical study in animal models demonstrated superior penetration of the BBB with osimertinib than gefitinib or afatinib and sustained tumor regression in an EGFR-mutant mouse brain metastasis model (29).

Together, positive CNS activity observed with these EGFR TKIs suggests that incorporation of EGFR TKIs in the treatment of asymptomatic brain metastases from EGFR-mutant NSCLC appears reasonable and these agents may be utilized upfront and radiation therapy reserved until progression to avoid radiation related neurotoxicity. Prospective evaluations of EGFR TKIs in active brain metastases and sequential approaches with brain radiotherapy are warranted.

\section{Anaplastic Lymphoma Kinase (ALK) Rearrangement}

A fusion gene comprising portions of echinoderm microtubule like protein 4 (EML4) and $A L K$ genes with resultant chimeric protein with constitutive kinase activity is found in approximately $2-7 \%$ of NSCLC $(30,31)$. Since its first discovery in 2007 , there have been rapid advances in the development of several TKIs targeting this genomic aberration. A first-generation ALK TKI, crizotinib, was shown to significantly improve PFS and ORR in both first- and second-line settings in patients with ALK-rearranged NSCLC, compared to chemotherapy (32, 33). For example, in a phase III randomized trial of first-line crizotinib, PFS was 10.9 with crizotinib compared to 7 months with chemotherapy and ORR was 74 and 45\%, respectively (33). Despite initial response, drug resistance invariably develops. Next-generation ALK TKIs, including ceritinib and alectinib, have been shown to be effective in patients with crizotinibresistant disease $(34,35)$.

Brain metastasis is a relatively common complication of $A L K$ rearranged NSCLC, especially at progression. In a retrospective study, incidence rates of brain metastases were $23.8 \%$ at diagnosis, $45.5 \%$ at 2 years, and $58.4 \%$ at 3 years (36). Crizotinib has been shown to be effective in treating brain metastases, at least initially, as suggested by a large retrospective pooled analysis of patients with asymptomatic brain metastases treated with this agent on the PROFILE 1005 and 1007 trials (37). In this study, an intracranial disease control rate was $56 \%$ at 12 weeks in patients with previously untreated brain metastases with a median time to CNS progression of 7 months. In a phase III randomized trial of first-line crizotinib versus platinum containing chemotherapy, patients with stable treated brain metastases were allowed to enroll (38). Intracranial efficacy assessment was part of this study. This study showed that among patients with brain metastases CNS disease control rate was significantly higher with crizotinib at 12 weeks ( 85 versus $45 \%$ ), and PFS was also significantly longer with crizotinib ( 9 versus 4 months). Recently two phase II trials of alectinib have shown remarkable CNS activity against brain metastases with CNS response rates up to $75 \%$ and median CNS disease response durations of 10-11 months $(39,40)$. Interestingly, the cumulative CNS progression rate at 12 months was lower than the cumulative non-CNS progression rate (24.8 versus $33.2 \%)$ (40).

\section{Immunotherapy}

Recently, there has been a significant development in immunotherapy to treat various types of cancer including NSCLC. Immune checkpoints, which exist to suppress immune response to protect against detrimental autoimmunity and inflammation, can be co-opted by tumors. Engagement of programmed death 1 (PD-1) receptor on activated $\mathrm{T}$ cells by programmed death ligand 1 (PD-L1) on tumor cells leads to T-cell inactivation, which in turn results in immune tolerance and subsequent progression of tumor. PD-1 inhibitors, including nivolumab and pembrolizumab, have shown to significantly improve ORR and survival outcomes in patients with metastatic NSCLC without other targetable mutations such as EGFR or ALK mutations. Both pembrolizumab and nivolumab were superior to docetaxel in previously treated patients $(41,42)$. Pembrolizumab was shown to be superior to platinum-containing doublet chemotherapy as first-line therapy in patients with NSCLC with more than $50 \%$ of tumor cells staining positive for PD-L1 (43). In another first-line trial, pembrolizumab combined with carboplatin and pemetrexed in PD-L1 unselected NSCLC patients was better than chemotherapy alone (44). These trials, however, excluded patients with active brain metastases. An early analysis of an ongoing trial (NCT02085070) investigating the activity and safety of pembrolizumab in NSCLC or melanoma patients with untreated or progressive brain metastases showed encouraging results (45). In this analysis, 6 (33\%) of 18 patients with NSCLC had brain response that was durable. There were no grade 3 or 4 neurological toxic effects.

\section{Squamous Cell Carcinoma}

Squamous cell carcinoma accounts for approximately $20 \%$ of all lung cancers. A genomic analysis of primary squamous cell lung cancer in 79 patients showed that $P I 3 K$ aberrant tumors had significantly worse overall survival (OS) (8.6 versus 18.8 months) and a higher incidence of brain metastases (27 versus $0 \%$ ) compared to FGFR1 aberrant tumors (9). The authors then analyzed six brain metastasis samples by whole-exome sequencing, four of these patients had matched samples of their primary lung cancer. This analysis showed heterozygous loss of PTEN in all of the brain metastasis samples with a pattern of gene expression consistent with PTEN loss. A deeper genomic analysis in this study demonstrated clonal heterogeneity with a low degree of shared events (as little as 15\%) between the brain metastases and their corresponding primary lung tumor. Further studies examining the exact role of aberrant PI3K pathway in the development of brain metastases and potential targeted therapy are warranted.

\section{BREAST CANCER}

Breast cancer is the most common cancer in women and second most common cancer to metastasize to the brain. The exact incidence of brain metastases from breast primary in the current era of modern therapies is unknown; however, a 10-year cumulative incidence of CNS relapse in patients presenting with early stage breast cancer is estimated to be around 4-5\% $(46,47)$. Triple receptor negative disease, basal-like subtype, and human 
epidermal growth factor receptor 2 (HER2) positive breast cancer have an increased risk of developing brain metastases $(46,48)$. Early ( $<2$ years after primary diagnosis) occurring brain metastases from breast primary are associated with early onset tumor, negative estrogen receptor (ER) status, HER2 overexpression, and triple receptor negative tumor (49). In comparison, many late occurring brain metastases are from ER positive primary tumors (50). Survival outcomes differ between different subtypes of breast cancer. The median OS after developing brain metastases was longer in patients with HER2-positive breast cancer at 11.5 months compared to luminal HER2 negative breast cancer at 9.3 months and triple receptor negative breast cancer at 4.9 months in a retrospective study of 1,256 patients (51).

Divergence of brain metastases from primary breast tumor has been suggested by several studies, in particular with regards to hormone receptor status. For example, retrospective studies reported a loss of hormone receptor expression in brain metastases compared to their corresponding breast primaries $(52,53)$, highlighting the importance of multisite tumor characterization, if clinically feasible, in the treatment decision making process. Molecular profiling of paired brain metastases and corresponding primary breast tumors by whole-exome sequencing revealed that brain metastases harbored genomic aberrations in the CDK pathway and PI3K/AKT/mTOR pathways, many alterations of which were not detected in the corresponding primary tumor (7).

A bioinformatics screen of genome-wide breast tumor methylation data available at The Cancer Genome Atlas (TGCA) and analysis of 11 pairs of primary breast tumors and their corresponding brain metastases identified three genes, GALNT9, $C C D C 8$, and $B N C 1$, that were frequently methylated $(55,73$, and $71 \%$, respectively) and silenced in brain metastases (50). Of these, GALNT9 and BNC1 were infrequently methylated in primary breast tumors, suggesting that they may be metastasis virulence genes and dysregulation of these occur as late events involved in brain colonization of these cancer cells. GALNT9, which is expressed most abundantly in the brain, plays an important role in $O$-glycosylation and, thereby, in cell adhesion and cell-cell communication. Cancer cells with aberrant GALNT9 that reach the brain are perhaps favored to proliferate in the new microenvironment through dysregulated cell-cell interaction. BNC1 encodes a zinc finger transcription factor that is involved in expression of a broad range of genes. Further studies are required to better understand the roles these mutations play in the development of brain metastases and to determine if they represent therapeutic targets.

\section{HER2 Overexpression}

Human epidermal growth factor receptor 2 protein overexpression and/or HER2 oncogene amplification is found in approximately $20 \%$ of all breast cancer patients (54). HER2 overexpression is associated with an increased risk of recurrence and death in the absence of adjuvant HER2-directed therapy, and it predicts response to anti-HER2 therapies. HER2-positive breast cancer carries an increased risk of brain metastases, and approximately $30-50 \%$ of patients with HER2-positive breast cancer will develop brain metastases during the course of disease (55), with a cumulative incidence of around $12 \%$ at 10 years and
$14 \%$ at 15 years $(46,56)$. The propensity of HER2-positive breast cancer to metastasize to the brain may be related to the improved survival of patients with HER2-directed therapy, the limited CNS penetration of HER2-directed agents, and the neurotropism of HER2-positive breast cancer (57). HER2-directed agents, including trastuzumab, pertuzumab, lapatinib, neratinib and T-DM1, significantly improve PFS and OS of patients with HER2-positive breast cancer. However, in a retrospective study, $24 \%$ of 182 patients with HER2-positive primary breast cancer had HER2 negative metastatic disease, and this discordance was associated with decreased survival (58). If feasible, HER2 status should be repeated in the metastatic disease, including brain metastasis, at relapse.

Trastuzumab, a monoclonal antibody against the HER2 receptor, has limited $\mathrm{CNS}$ activity due to its inability to cross the intact BBB. However, there is some evidence of an improved CNS penetration of trastuzumab after disruption of the BBB by radiation therapy. For example, a pharmacokinetic study showed that the ratio of the CSF to plasma levels of trastuzumab in patients with brain metastasis improved significantly from 1:420 before radiotherapy to 1:76 after radiotherapy (59). In patients with concomitant leptomeningeal carcinomatosis, the CSF to plasma ratio after radiotherapy was 1:49. Pertuzumab, another monoclonal antibody against the HER2 receptor, has a significant synergistic antitumor activity in combination with trastuzumab and docetaxel as shown in a randomized phase III placebocontrolled trial of pertuzumab, the CLEOPATRA trial (60). In exploratory analyses of this trial, the median time to development of brain metastases as first site of disease progression was significantly longer in the pertuzumab arm compared to the placebo arm (15.0 versus 11.9 months), and the median OS was 34.4 months in the pertuzumab arm, compared to 26.3 month in the placebo arm (61). Pertuzumab with high-dose trastuzumab in HER2-positive breast cancer patients with brain metastases after radiotherapy is currently under clinical evaluation in a phase II trial (NCT02536339). There is also an ongoing trial of intrathecal pertuzumab and trastuzumab in patients with new untreated asymptomatic or low symptomatic brain metastasis in HER2-positive breast cancer (NCT02598427). Lapatinib is a TKI that acts against both HER2 and EGFR receptors. It has been shown that this agent is able to cross the BBB. In the presence of brain metastases, the brain to plasma concentration of lapatinib was higher at $26 \%$ compared to the normal brain parenchyma where the concentration was low at $1.3-2.8 \%$ (62). However, the intracranial response to lapatinib alone has been shown to be low at $3-6 \%(63,64)$. In a multicenter phase II study, 45 patients with previously untreated brain metastases from HER2-positive breast cancer were treated with lapatinib and capecitabine combination (55). The addition of capecitabine to lapatinib resulted in an encouraging intracranial response rate of $66 \%$ with a median time to intracranial progression of 5.5 months.

\section{PI3K/AKT/mTOR Pathway}

Actionable mutations in $\mathrm{PI} 3 \mathrm{~K} / \mathrm{AKT} / \mathrm{mTOR}$ pathway are frequent in breast cancer brain metastases (7). The addition of everolimus, an mTOR inhibitor, to an aromatase inhibitor in patients with hormone receptor positive metastatic breast cancer and to 
trastuzumab and vinorelbine in patients with HER2-positive breast cancer led to improved survival outcomes in randomized placebo-controlled phase III trials $(65,66)$. Everolimus crosses the $\mathrm{BBB}$ as shown in patients with primary brain tumors. The role of everolimus in the management of patients with breast cancer brain metastases is currently being investigated in clinical trials (NCT01305941, NCT01783756).

\section{Cyclin D-Cyclin-Dependent Kinase 4/6-INK4-Rb Pathway}

Activation of cyclin-dependent kinase 4 and 6 (CDK4 and CDK6) by cyclin $\mathrm{D}$ leads to cell proliferation by initiating transition from the G1 phase to the S phase in cell cycle via phosphorylation of retinoblastoma protein $(\mathrm{Rb})$. Alterations in this pathway are frequent in various cancer types. CDK inhibitors, such as palbociclib, abemaciclib, and ribociclib, have shown high efficacy in patients with hormone receptor positive breast cancer (67). Good CNS penetration of abemaciclib was recently shown (68). There are ongoing trials investigating these agents in patients with breast cancer brain metastases (NCT02896335, NCT02774681, NCT02308020).

\section{MELANOMA}

Melanoma is the third most common malignancy to metastasize to the brain. It is estimated that at least $50 \%$ of patients with stage IV melanoma will develop brain metastases during the course of disease (69). With supportive care alone, the median survival from developing brain metastases is only around 2 months (70).

\section{Mitogen Activated Protein Kinase (MAPK) Pathway}

About half of melanoma patients have an activating mutation in $B R A F$, an oncogene involved in the MAPK pathway that is a key regulator of cell growth, division, and differentiation (71). The most common $B R A F$ mutation is the substitution of valine for glutamic acid (VAL600Glu or V600E) accounting for approximately $90 \%$ of all BRAF mutations seen in melanoma. BRAF V600E mutant melanoma tends to be more aggressive. BRAF inhibitors, including dabrafenib and vemurafenib, significantly improve survival in patients with metastatic $B R A F$ mutant melanoma $(72,73)$. In a multicenter phase II trial, 172 patients with $B R A F$ mutant melanoma with at least one asymptomatic brain metastasis were treated with dabrafenib (74). Patients were divided into two cohorts: those with and without previous local treatments for brain disease. Dabrafenib was active in both cohorts with ORR of $39.2 \%$ in patients without previous local therapy and $30.8 \%$ in those with previously treated brain metastases and median OS of 33 and 31 weeks, respectively. A retrospective study of 27 patients treated with vemurafenib for their BRAF mutant melanoma that had metastasized to the brain reported intracranial ORR of $50 \%$ and extracranial ORR of $71 \%$ (75). The median intracranial PFS was 4.6 months, and median OS was 7.5 months. Next-generation sequencing analysis of poorly responding brain metastases revealed co-occurring mutations in genes predicted to activate the PI3K/AKT pathway.
MEK kinase, which is downstream of BRAF, is activated by CRAF or members of the PI3K pathway as an escape mechanism from BRAF inhibition. When BRAF inhibitors were combined with MEK inhibitors, the efficacy was further improved in patients with extracranial disease, as evidenced by prolonged PFS and OS shown in phase III trials (76-78). This approach of dual BRAF and MEK inhibition therapy in patients with brain metastases is currently being evaluated in clinical trials (NCT02039947, NCT02537600).

\section{PI3K/AKT/mTOR Pathway}

A molecular analysis of 16 matched pairs of melanoma brain metastases and extracranial metastases showed that activation of the PI3K/AKT/mTOR pathway was enriched in the brain metastases (8). Preclinical cell culture and animal studies of a PI3K inhibitor, BKM120, demonstrated that this agent inhibited the growth of cell lines derived from melanoma brain metastases with inhibition rates of up to $80 \%$ and potently induced apoptosis and significantly inhibited the tumor growth of human brain metastatic melanoma cells in the brain of nude mice (79). These findings suggest the potential of PI3K inhibitors as adjunct targeted therapy in the treatment of advanced melanoma that has metastasized to the brain.

\section{Immunotherapy}

There has been dramatic improvement in survival of patients with advanced melanoma in recent years with the development of modern immunotherapy including cytotoxic T lymphocyte antigen-4 (CTLA-4) inhibitors and programmed death-1 (PD-1) checkpoint inhibitors. CTLA-4 plays an important role in the regulation of immune activation and tolerance (80). Its signaling inhibits T-cell activation. Ipilimumab is an inhibitor of CTLA-4 that was shown to improve OS in patients with metastatic melanoma compared to a peptide vaccine in a phase III trial (81). A phase II study of ipilimumab was conducted in 72 melanoma patients with brain metastases (82). The disease control rate was $24 \%$ in patients who were asymptomatic from their brain disease and were not on corticosteroid treatment. One- and two-year survival rates were 31 and $26 \%$ in this steroid-independent cohort. Interaction between PD-1 receptor and PD-ligand 1 (PD-L1) inhibits cytotoxic T-cell activity. PD-1 inhibitors, including nivolumab and pembrolizumab, have resulted in significantly improved survival outcomes in patients with advanced melanoma $(83,84)$. Pembrolizumab is currently under clinical evaluation in patients with brain metastases from melanoma (NCT02085070). Interim analysis from a phase II trial reported an intracranial ORR of $22 \%$ (45). In a randomized phase III trial, nivolumab and ipilimumab combination was shown to be superior to either drug alone in patients with advanced melanoma without brain metastases (85). Median PFS was 11.5 months in the combination arm compared to 6.9 months in the nivolumab alone arm and 2.9 months in the ipilimumab alone arm. There are ongoing trials evaluating the dual CTLA-4 and PD-1 inhibition therapy in melanoma patients with brain metastases (NCT02320058, NCT02621515).

Table 1 summarizes actionable mutations in brain metastases of NSCLC, breast cancer and melanoma, and their targeted therapies discussed earlier. 
TABLE 1 | Overview of actionable mutations in brain metastases of non-small cell lung cancer, breast cancer and melanoma, and potential targeted therapies.

\begin{tabular}{|c|c|c|c|c|c|}
\hline Cancer type & Mutation & Targeted therapy & $\begin{array}{l}\text { Objective response } \\
\text { rate }(\%)\end{array}$ & $\begin{array}{l}\text { Progression-free survival } \\
\text { (months) }\end{array}$ & $\begin{array}{c}\text { Reference or } \\
\text { clinicaltrials.gov number }\end{array}$ \\
\hline \multirow[t]{8}{*}{$\begin{array}{l}\text { Non-small cell } \\
\text { lung cancer }\end{array}$} & \multirow[t]{2}{*}{$\begin{array}{l}\text { Activating EGFR } \\
\text { mutation }\end{array}$} & $\begin{array}{l}\text { First-generation EGFR TKIs: gefitinib, } \\
\text { erlotinib }\end{array}$ & $58-83$ & $7-15$ & $(23-26)$ \\
\hline & & ErbB family inhibitor: afatinib & $70-75$ & 8 & (21) \\
\hline & \multirow[t]{2}{*}{ EGFR T790M } & \multirow[t]{2}{*}{ T790M specific EGFR TKI: osimertinib } & \multirow[t]{2}{*}{ NA } & $\mathrm{NA}$ & (29) \\
\hline & & & & $\begin{array}{l}\text { Superior blood-brain barrier } \\
\text { penetration than gefitinib } \\
\text { or afatinib demonstrated in } \\
\text { preclinical study }\end{array}$ & \\
\hline & \multirow[t]{2}{*}{$A L K$ rearrangement } & First-generation ALK TKI: crizotinib & $56-85$ & $7-9$ & $(37,38)$ \\
\hline & & Second-generation ALK TKI: alectinib & 75 & $10-11$ & $(39,40)$ \\
\hline & \multirow[t]{2}{*}{ (No specific mutation) } & \multirow[t]{2}{*}{ PD-1 inhibitor: pembrolizumab } & NA & \multirow[t]{2}{*}{ NA } & \multirow[t]{2}{*}{ NCT02085070 (45) } \\
\hline & & & $\begin{array}{c}\text { Early analysis showed } \\
33 \% \text { intracranial } \\
\text { response rate }\end{array}$ & & \\
\hline \multirow[t]{7}{*}{ Breast cancer } & \multirow[t]{2}{*}{$\begin{array}{l}\text { HER2 } \\
\text { overexpression/HER2 } \\
\text { oncogene amplification }\end{array}$} & $\begin{array}{l}\text { Dual anti-HER2 inhibition: pertuzumab } \\
\text { plus trastuzumab }\end{array}$ & NA & NA & $\begin{array}{l}\text { Intravenous: NCT02536339 } \\
\text { Intrathecal: NCT02598427 }\end{array}$ \\
\hline & & $\begin{array}{l}\text { HER2/EGFR TKI: lapatinib (in } \\
\text { combination with capecitabine) }\end{array}$ & 66 & 5.5 & (55) \\
\hline & \multirow{5}{*}{$\begin{array}{l}\text { Mutation in PI3K/AKT/ } \\
\text { mTOR pathway } \\
\text { Mutation in CDK } 4 / 6 \\
\text { pathway }\end{array}$} & \multirow[t]{2}{*}{ mTOR inhibitor: everolimus } & \multirow[t]{2}{*}{ NA } & \multirow[t]{2}{*}{ NA } & NCT01305941 \\
\hline & & & & & NCT01783756 \\
\hline & & \multirow[t]{3}{*}{ CDK inhibitors } & \multirow[t]{3}{*}{ NA } & \multirow[t]{3}{*}{ NA } & NCT02896335 \\
\hline & & & & & NCT02774681 \\
\hline & & & & & NCT02308020 \\
\hline \multirow[t]{10}{*}{ Melanoma } & \multirow{4}{*}{$\begin{array}{l}\text { Activating } B R A F \\
\text { mutation }\end{array}$} & BRAF inhibitors: dabrafenib & 39 & 16 & $(74)$ \\
\hline & & Vemurafenib & 50 & 4.6 & (75) \\
\hline & & $\begin{array}{l}\text { Dual BRAF/MEK inhibition: } \\
\text { dabrafenib + trametinib }\end{array}$ & NA & NA & NCT02039947 \\
\hline & & Vemurafenib + cobimetinib & NA & NA & NCT02537600 \\
\hline & \multirow{2}{*}{$\begin{array}{l}\text { Mutation in PI3K/AKT/ } \\
\text { mTOR pathway }\end{array}$} & \multirow[t]{2}{*}{ PI3K inhibitor: BKM120 } & \multirow[t]{2}{*}{ NA } & NA & $(79)$ \\
\hline & & & & $\begin{array}{l}\text { Efficacy demonstrated in } \\
\text { preclinical study }\end{array}$ & \\
\hline & \multirow[t]{4}{*}{ (No specific mutation) } & CTLA-4 inhibitor: ipilimumab & 24 & 2.7 & (82) \\
\hline & & PD-1 inhibitor: pembrolizumab & NA & NA & NCT02085070 \\
\hline & & \multirow{2}{*}{$\begin{array}{l}\text { Dual CTLA-4/PD-1 inhibition: } \\
\text { ipilimumab + nivolumab }\end{array}$} & \multirow[t]{2}{*}{ NA } & \multirow[t]{2}{*}{ NA } & NCT02320058 \\
\hline & & & & & NCT02621515 \\
\hline
\end{tabular}

EGFR, epidermal growth factor receptor; TKI, tyrosine kinase inhibitor; ALK, anaplastic lymphoma kinase; PD-1, programmed death 1; HER2, human epidermal growth factor receptor 2; PI3K, phosphoinositide 3-kinase; mTOR, mammalian target of rapamycin; CDK4/6, cyclin-dependent kinase 4 and 6; CTLA-4, cytotoxic T lymphocyte antigen-4; NA, not available.

\section{COLORECTAL CANCER}

While colorectal cancer is the third most common cancer in men and second in women, brain metastases are relatively rare with an incidence rate of $1.55 \%$ (86). A systematic review and pooled data analysis from 16 relevant studies showed that rectal location was associated with an increased risk of brain metastases compared to other colon locations. The presence of pulmonary metastases was also associated with an increased risk. The incidence of brain metastases from colorectal cancer may be increasing as a result of improved systemic therapy and survival of patients. The prognosis is poor with a reported median OS of 2.6-7.4 months after developing brain metastases (86).

\section{RAS Mutation}

KRAS and NRAS mutations are the most extensively investigated somatic mutations in metastatic colorectal cancers, and they predict tumor resistance to anti-EGFR therapy, such as cetuximab and panitumumab. There have been several studies examining these mutations in patients with brain metastases from colorectal cancer. A retrospective analysis of 918 patients with metastatic colorectal cancer who were genotyped for RAS mutations showed a significantly higher cumulative incidence of brain metastases at 2 years in patients with RAS mutation compared to those without (1.4 versus $0.2 \%$ ) (87). Nearly two-thirds of the brain metastasis cases occurred in patients with RAS mutant colorectal cancer. Currently, there are no RAS inhibitors available for clinical use.

\section{BRAF Mutation}

$B R A F$ activation mutations (most commonly V600E) occur in less than $10 \%$ of metastatic colorectal cancer and are associated with poorer survival. BRAF V600E mutations confer resistance to anti-EGFR therapy. To date, no clear association between $B R A F$ mutation and development of brain metastases has been observed $(88,89)$. A clinical characterization of 524 metastatic colorectal cancer patients with known $B R A F$ mutation status, where 57 patients had $B R A F$ mutation, found no difference in 
the incidence of brain metastases between patients with $B R A F$ mutant tumors and those with wild-type tumors (88).

\section{PIK3CA Mutation}

PIK3CA mutations are found in approximately $10-15 \%$ of primary colorectal cancers. In a genomic analysis of colorectal metastases from different sites, PIK3CA mutation frequency was higher in brain and lung metastases compared with liver metastases (23.9\% in brain, $20 \%$ in lung, $7.7 \%$ in liver) (89) Another study also found an association between PIK3CA mutations and brain metastases with a 2 -year cumulative incidence of $1.4 \%$, compared to $0.8 \%$ in patients with no PIK3CA mutation (87). However, this observation is difficult to interpret as many of those patients with PIK3CA mutation and brain metastases also had RAS mutations.

\section{RENAL CELL CARCINOMA}

Approximately $3.5-17 \%$ of patients with renal cell carcinoma develop brain metastases (69). Reported median OS after developing brain metastases ranges from 4.1 to 15 months (69). Patients with bone and thoracic metastases were found to have a higher rate of brain metastases compared to those with abdominal metastases (16 versus 2\%) (90). An association between the loss of chromosome 9 and brain metastases was also observed (91). Registration-directed clinical trials investigating therapies for angiogenesis, mTOR signaling, and immunotherapy have excluded patients with brain metastases. Patients with brain metastases were included in the European Advanced RCC Sorafenib expanded-access study in which sorafenib, a VEGF TKI, was given to patients with previously treated advanced renal cell carcinoma. It was shown that the sorafenib safety profile in patients with brain metastases was similar to the overall study population (92). In a prospective open-label non-interventional study in a broad population of patients with advanced renal cell carcinoma treated with sorafenib in routine clinical practice, 115 patients (5\% of total study population) had brain metastases (93). The median duration of therapy for this subgroup was similar to that of the total study population (7.0 versus 7.3 months), suggesting that sorafenib has activity in the CNS. In a retrospective study, treatment with TKI was associated with an improved median OS from developing brain metastases (94). However, in prospective studies, the response to these drugs has been more modest. A reported median PFS and OS were only 5.3 and 8.2 months, respectively, in patients with brain metastases treated with sunitinib as part of the global expanded-access protocol (95).

Genetic divergence of brain metastases from primary renal cell carcinoma has been shown recently in a genomic study of paired brain and primary tumors (7). In this study, some brain metastases from renal cell carcinoma had PTEN, PIK3CA, and CDKN2A mutations that were not detected in the corresponding primary tumors. Mutations in $\mathrm{PI} 3 \mathrm{~K} / \mathrm{ATK} / \mathrm{mTOR}$ pathway may be potential drivers in brain metastases development and therefore warrant further investigations.

In a randomized phase III trial, the treatment with nivolumab improved survival outcomes compared with everolimus in patients with previously treated advanced renal cell carcinoma (96). Unfortunately, patients with brain metastases were excluded.
Clinical trials investigating the role of nivolumab or pembrolizumab in patients with brain metastases is currently underway (NCT02978404, NCT02596035, NCT02886585).

\section{OVARIAN CANCER}

Brain metastases from ovarian cancer are very rare with reported incidence rates ranging from 0.29 to $5 \%$; however, the incidence has been rising since the introduction of platinum-based chemotherapy (97). In a recent next-generation sequencing-based genomic analysis of eight brain metastases of primary ovarian cancer, all eight brain metastasis samples harbored mutations in at least one DNA repair gene with seven of eight samples revealing either a BRCA1 or BRCA2 mutation (98). Other commonly observed mutations include TP53, ATM, and CHEK2 mutations. These findings suggest that BRCA and DNA repair malfunction may possibly play a role in ovarian cancer metastasizing to the brain. A mutation in ATM, a regulator of DNA damage detection and repair via phosphorylation of a wide variety of downstream proteins including TP53 and BRCA1, may also play a role in the development of brain metastases (98). In cancers that lack homologous repair capacity due to BRCA1/2 or ATM dysfunction or loss, PARP inhibitors can lead to cancer cell death via mechanisms of synthetic lethality (99). PARP inhibitors, olaparib and veliparib, have been shown to have activity in the CNS $(100,101)$, therefore they represent a potential targeted therapy in these cancers with genetic alterations in genes involved in DNA damage response and repair.

\section{CONCLUSION}

The incidence of brain metastases is rising as modern cancer therapy is improving the survival of patients with advanced cancer. There is mounting evidence of genomic heterogeneity intratumorally as well as across different metastatic sites. Recently, genomic analyses of brain metastases and matching primary tumors have revealed that brain metastases can harbor actionable driver mutations that are not present in the primary tumors or other extracranial metastases. This genomic divergence of brain metastases from their primary tumors may contribute to the clinically observed treatment response disparities. Cancer genomic analysis using novel and far less invasive approaches, such as cell-free ctDNA in the CSF obtained via a lumbar puncture in the outpatient clinics, is very promising in providing critical information required for personalized genomic-directed therapy in patients with brain metastases. Moreover, these new less invasive genomic analysis techniques are more feasible even in patients who are not surgical candidates and can be repeated to determine tumor response to treatment or detect early progression during surveillance. Compared to the traditional chemotherapeutics, next-generation targeted agents appear to be more effective in controlling the CNS disease with better safety profiles. Several brain metastases-dedicated trials of various targeted therapies are currently underway to address the role of these agents in the treatment of CNS disease.

\section{AUTHOR CONTRIBUTIONS}

All the authors contributed to the manuscript. 


\section{REFERENCES}

1. Nayak L, Lee EQ, Wen PY. Epidemiology of brain metastases. Curr Oncol Rep (2012) 14(1):48-54. doi:10.1007/s11912-011-0203-y

2. Berghoff AS, Bartsch R, Wohrer A, Streubel B, Birner P, Kros JM, et al. Predictive molecular markers in metastases to the central nervous system: recent advances and future avenues. Acta Neuropathol (2014) 128(6):879-91. doi:10.1007/s00401-014-1350-7

3. Brastianos PK, Curry WT, Oh KS. Clinical discussion and review of the management of brain metastases. J Natl Compr Canc Netw (2013) 11(9):1153-64. doi:10.6004/jnccn.2013.0133

4. Lockman PR, Mittapalli RK, Taskar KS, Rudraraju V, Gril B, Bohn KA, et al. Heterogeneous blood-tumor barrier permeability determines drug efficacy in experimental brain metastases of breast cancer. Clin Cancer Res (2010) 16(23):5664-78. doi:10.1158/1078-0432.CCR-10-1564

5. Gerlinger M, Rowan AJ, Horswell S, Larkin J, Endesfelder D, Gronroos E, et al. Intratumor heterogeneity and branched evolution revealed by multiregion sequencing. N Engl J Med (2012) 366(10):883-92. doi:10.1056/ NEJMoa1113205

6. Lee SY, Haq F, Kim D, Jun C, Jo HJ, Ahn SM, et al. Comparative genomic analysis of primary and synchronous metastatic colorectal cancers. PLoS One (2014) 9(3):e90459. doi:10.1371/journal.pone.0090459

7. Brastianos PK, Carter SL, Santagata S, Cahill DP, Taylor-Weiner A, Jones RT, et al. Genomic characterization of brain metastases reveals branched evolution and potential therapeutic targets. Cancer Discov (2015) 5(11):1164-77. doi:10.1158/2159-8290.CD-15-0369

8. Chen G, Chakravarti N, Aardalen K, Lazar AJ, Tetzlaff MT, Wubbenhorst B, et al. Molecular profiling of patient-matched brain and extracranial melanoma metastases implicates the PI3K pathway as a therapeutic target. Clin Cancer Res (2014) 20(21):5537-46. doi:10.1158/1078-0432.CCR-13-3003

9. Paik PK, Shen R, Won H, Rekhtman N, Wang L, Sima CS, et al. Next-generation sequencing of stage IV squamous cell lung cancers reveals an association of PI3K aberrations and evidence of clonal heterogeneity in patients with brain metastases. Cancer Discov (2015) 5(6):610-21. doi:10.1158/2159-8290. CD-14-1129

10. Wikman H, Lamszus K, Detels N, Uslar L, Wrage M, Benner C, et al. Relevance of PTEN loss in brain metastasis formation in breast cancer patients. Breast Cancer Res (2012) 14(2):R49. doi:10.1186/bcr3150

11. Dawson SJ, Tsui DW, Murtaza M, Biggs H, Rueda OM, Chin SF, et al. Analysis of circulating tumor DNA to monitor metastatic breast cancer. $N$ Engl J Med (2013) 368(13):1199-209. doi:10.1056/NEJMoa1213261

12. De Mattos-Arruda L, Mayor R, Ng CK, Weigelt B, Martinez-Ricarte F, Torrejon D, et al. Cerebrospinal fluid-derived circulating tumour DNA better represents the genomic alterations of brain tumours than plasma. Nat Commun (2015) 6:8839. doi:10.1038/ncomms9839

13. Murtaza M, Dawson SJ, Tsui DW, Gale D, Forshew T, Piskorz AM, et al. Non-invasive analysis of acquired resistance to cancer therapy by sequencing of plasma DNA. Nature (2013) 497(7447):108-12. doi:10.1038/nature12065

14. Pentsova EI, Shah RH, Tang J, Boire A, You D, Briggs S, et al. Evaluating cancer of the central nervous system through next-generation sequencing of cerebrospinal fluid. JClin Oncol (2016) 34(20):2404-15. doi:10.1200/ JCO.2016.66.6487

15. Hubbs JL, Boyd JA, Hollis D, Chino JP, Saynak M, Kelsey CR. Factors associated with the development of brain metastases: analysis of 975 patients with early stage nonsmall cell lung cancer. Cancer (2010) 116(21):5038-46. doi:10.1002/cncr.25254

16. Consonni D, Pierobon M, Gail MH, Rubagotti M, Rotunno M, Goldstein A, et al. Lung cancer prognosis before and after recurrence in a population-based setting. J Natl Cancer Inst (2015) 107(6):djv059. doi:10.1093/jnci/djv059

17. Hsu F, De Caluwe A, Anderson D, Nichol A, Toriumi T, Ho C. EGFR mutation status on brain metastases from non-small cell lung cancer. Lung Cancer (2016) 96:101-7. doi:10.1016/j.lungcan.2016.04.004

18. Mok TS, Wu YL, Thongprasert S, Yang CH, Chu DT, Saijo N, et al. Gefitinib or carboplatin-paclitaxel in pulmonary adenocarcinoma. N Engl J Med (2009) 361(10):947-57. doi:10.1056/NEJMoa0810699

19. Rosell R, Carcereny E, Gervais R, Vergnenegre A, Massuti B, Felip E, et al. Erlotinib versus standard chemotherapy as first-line treatment for European patients with advanced EGFR mutation-positive non-small-cell lung cancer
(EURTAC): a multicentre, open-label, randomised phase 3 trial. Lancet Oncol (2012) 13(3):239-46. doi:10.1016/S1470-2045(11)70393-X

20. Sequist LV, Yang JC, Yamamoto N, O’Byrne K, Hirsh V, Mok T, et al. Phase III study of afatinib or cisplatin plus pemetrexed in patients with metastatic lung adenocarcinoma with EGFR mutations. J Clin Oncol (2013) 31(27):3327-34. doi:10.1200/JCO.2012.44.2806

21. Schuler M, Wu YL, Hirsh V, O’Byrne K, Yamamoto N, Mok T, et al. Firstline afatinib versus chemotherapy in patients with non-small cell lung cancer and common epidermal growth factor receptor gene mutations and brain metastases. J Thorac Oncol (2016) 11(3):380-90. doi:10.1016/ j.jtho.2015.11.014

22. Hoffknecht P, Tufman A, Wehler T, Pelzer T, Wiewrodt R, Schutz M, et al. Efficacy of the irreversible ErbB family blocker afatinib in epidermal growth factor receptor (EGFR) tyrosine kinase inhibitor (TKI)-pretreated non-smallcell lung cancer patients with brain metastases or leptomeningeal disease. J Thorac Oncol (2015) 10(1):156-63. doi:10.1097/JTO.0000000000000380

23. Porta R, Sanchez-Torres JM, Paz-Ares L, Massuti B, Reguart N, Mayo C, et al. Brain metastases from lung cancer responding to erlotinib: the importance of EGFR mutation. Eur Respir J (2011) 37(3):624-31. doi:10.1183/ 09031936.00195609

24. Song Z, Zhang Y. Gefitinib and erlotinib for non-small cell lung cancer patients who fail to respond to radiotherapy for brain metastases. J Clin Neurosci (2014) 21(4):591-5. doi:10.1016/j.jocn.2013.05.022

25. Wu YL, Zhou C, Cheng Y, Lu S, Chen GY, Huang C, et al. Erlotinib as second-line treatment in patients with advanced non-small-cell lung cancer and asymptomatic brain metastases: a phase II study (CTONG-0803). Ann Oncol (2013) 24(4):993-9. doi:10.1093/annonc/mds529

26. Park SJ, Kim HT, Lee DH, Kim KP, Kim SW, Suh C, et al. Efficacy of epidermal growth factor receptor tyrosine kinase inhibitors for brain metastasis in nonsmall cell lung cancer patients harboring either exon 19 or 21 mutation. Lung Cancer (2012) 77(3):556-60. doi:10.1016/j.lungcan.2012.05.092

27. Janne PA, Yang JC, Kim DW, Planchard D, Ohe Y, Ramalingam SS, et al. AZD9291 in EGFR inhibitor-resistant non-small-cell lung cancer. $N$ Engl J Med (2015) 372(18):1689-99. doi:10.1056/NEJMoa1411817

28. Yu HA, Arcila ME, Rekhtman N, Sima CS, Zakowski MF, Pao W, et al. Analysis of tumor specimens at the time of acquired resistance to EGFR-TKI therapy in 155 patients with EGFR-mutant lung cancers. Clin Cancer Res (2013) 19(8):2240-7. doi:10.1158/1078-0432.CCR-12-2246

29. Ballard P, Yates JW, Yang Z, Kim DW, Yang JC, Cantarini M, et al. Preclinical comparison of osimertinib with other EGFR-TKIs in EGFR-mutant NSCLC brain metastases models, and early evidence of clinical brain metastases activity. Clin Cancer Res (2016) 22(20):5130-40. doi:10.1158/1078-0432. CCR-16-0399

30. Kwak EL, Bang YJ, Camidge DR, Shaw AT, Solomon B, Maki RG, et al. Anaplastic lymphoma kinase inhibition in non-small-cell lung cancer. $N$ Engl J Med (2010) 363(18):1693-703. doi:10.1056/NEJMoa1006448

31. Soda M, Choi YL, Enomoto M, Takada S, Yamashita Y, Ishikawa S, et al. Identification of the transforming EML4-ALK fusion gene in non-small-cell lung cancer. Nature (2007) 448(7153):561-6. doi:10.1038/nature05945

32. Shaw AT, Kim DW, Nakagawa K, Seto T, Crino L, Ahn MJ, et al. Crizotinib versus chemotherapy in advanced ALK-positive lung cancer. $N$ Engl J Med (2013) 368(25):2385-94. doi:10.1056/NEJMoa1214886

33. Solomon BJ, Mok T, Kim DW, Wu YL, Nakagawa K, Mekhail T, et al. First-line crizotinib versus chemotherapy in ALK-positive lung cancer. $N$ Engl J Med (2014) 371(23):2167-77. doi:10.1056/NEJMoa1408440

34. Gainor JF, Tan DS, De Pas T, Solomon BJ, Ahmad A, Lazzari C, et al. Progression-free and overall survival in ALK-positive NSCLC patients treated with sequential crizotinib and ceritinib. Clin Cancer Res (2015) 21(12):2745-52. doi:10.1158/1078-0432.CCR-14-3009

35. Shaw AT, Kim DW, Mehra R, Tan DS, Felip E, Chow LQ, et al. Ceritinib in ALKrearranged non-small-cell lung cancer. N Engl J Med (2014) 370(13):1189-97. doi:10.1056/NEJMoa1311107

36. Rangachari D, Yamaguchi N, VanderLaan PA, Folch E, Mahadevan A, Floyd SR, et al. Brain metastases in patients with EGFR-mutated or ALKrearranged non-small-cell lung cancers. Lung Cancer (2015) 88(1):108-11. doi:10.1016/j.lungcan.2015.01.020

37. Costa DB, Shaw AT, Ou SH, Solomon BJ, Riely GJ, Ahn MJ, et al. Clinical experience with crizotinib in patients with advanced ALK-rearranged 
non-small-cell lung cancer and brain metastases. JClin Oncol (2015) 33(17):1881-8. doi:10.1200/JCO.2014.59.0539

38. Solomon BJ, Cappuzzo F, Felip E, Blackhall FH, Costa DB, Kim DW, et al. Intracranial efficacy of crizotinib versus chemotherapy in patients with advanced ALK-positive non-small-cell lung cancer: results from PROFILE 1014. J Clin Oncol (2016) 34(24):2858-65. doi:10.1200/JCO.2015.63.5888

39. Shaw AT, Gandhi L, Gadgeel S, Riely GJ, Cetnar J, West H, et al. Alectinib in ALK-positive, crizotinib-resistant, non-small-cell lung cancer: a single-group, multicentre, phase 2 trial. Lancet Oncol (2016) 17(2):234-42. doi:10.1016/ S1470-2045(15)00488-X

40. Ou SH, Ahn JS, De Petris L, Govindan R, Yang JC, Hughes B, et al. Alectinib in crizotinib-refractory ALK-rearranged non-small-cell lung cancer: a phase II global study. J Clin Oncol (2016) 34(7):661-8. doi:10.1200/JCO.2015.63.9443

41. Borghaei H, Paz-Ares L, Horn L, Spigel DR, Steins M, Ready NE, et al. Nivolumab versus docetaxel in advanced nonsquamous non-small-cell lung cancer. N Engl J Med (2015) 373(17):1627-39. doi:10.1056/NEJMoa1507643

42. Herbst RS, Baas P, Kim DW, Felip E, Perez-Gracia JL, Han JY, et al. Pembrolizumab versus docetaxel for previously treated, PD-L1-positive, advanced non-small-cell lung cancer (KEYNOTE-010): a randomised controlled trial. Lancet (2016) 387(10027):1540-50. doi:10.1016/ S0140-6736(15)01281-7

43. Reck M, Rodriguez-Abreu D, Robinson AG, Hui R, Csoszi T, Fulop A, et al. Pembrolizumab versus chemotherapy for PD-L1-positive non-small-cell lung cancer. N Engl J Med (2016) 375(19):1823-33. doi:10.1056/NEJMoa1606774

44. Langer CJ, Gadgeel SM, Borghaei H, Papadimitrakopoulou VA, Patnaik A, Powell SF, et al. Carboplatin and pemetrexed with or without pembrolizumab for advanced, non-squamous non-small-cell lung cancer: a randomised, phase 2 cohort of the open-label KEYNOTE-021 study. Lancet Oncol (2016) 17(11):1497-508. doi:10.1016/S1470-2045(16)30498-3

45. Goldberg SB, Gettinger SN, Mahajan A, Chiang AC, Herbst RS, Sznol M, et al. Pembrolizumab for patients with melanoma or non-small-cell lung cancer and untreated brain metastases: early analysis of a non-randomised, open-label, phase 2 trial. Lancet Oncol (2016) 17(7):976-83. doi:10.1016/ S1470-2045(16)30053-5

46. Arvold ND, Oh KS, Niemierko A, Taghian AG, Lin NU, Abi-Raad RF, et al. Brain metastases after breast-conserving therapy and systemic therapy: incidence and characteristics by biologic subtype. Breast Cancer Res Treat (2012) 136(1):153-60. doi:10.1007/s10549-012-2243-x

47. Pestalozzi BC, Zahrieh D, Price KN, Holmberg SB, Lindtner J, Collins J, et al. Identifying breast cancer patients at risk for Central Nervous System (CNS) metastases in trials of the International Breast Cancer Study Group (IBCSG). Ann Oncol (2006) 17(6):935-44. doi:10.1093/annonc/mdl064

48. Shen Q, Sahin AA, Hess KR, Suki D, Aldape KD, Sawaya R, et al. Breast cancer with brain metastases: clinicopathologic features, survival, and paired biomarker analysis. Oncologist (2015) 20(5):466-73. doi:10.1634/theoncologist.2014-0107

49. Sanna G, Franceschelli L, Rotmensz N, Botteri E, Adamoli L, Marenghi C, et al. Brain metastases in patients with advanced breast cancer. Anticancer Res (2007) 27(4C):2865-9.

50. Pangeni RP, Channathodiyil P, Huen DS, Eagles LW, Johal BK, Pasha D, et al. The GALNT9, BNC1 and CCDC8 genes are frequently epigenetically dysregulated in breast tumours that metastasise to the brain. Clin Epigenetics (2015) 7:57. doi:10.1186/s13148-015-0089-x

51. Niikura N, Hayashi N, Masuda N, Takashima S, Nakamura R, Watanabe K, etal. Treatment outcomes and prognostic factors for patients with brain metastases from breast cancer of each subtype: a multicenter retrospective analysis. Breast Cancer Res Treat (2014) 147(1):103-12. doi:10.1007/s10549-014-3090-8

52. Bachmann C, Grischke EM, Fehm T, Staebler A, Schittenhelm J, Wallwiener D. CNS metastases of breast cancer show discordant immunohistochemical phenotype compared to primary. J Cancer Res Clin Oncol (2013) 139(4):551-6. doi:10.1007/s00432-012-1358-0

53. Hoefnagel LD, van de Vijver MJ, van Slooten HJ, Wesseling P, Wesseling J, Westenend PJ, et al. Receptor conversion in distant breast cancer metastases. Breast Cancer Res (2010) 12(5):R75. doi:10.1186/bcr2645

54. Owens MA, Horten BC, Da Silva MM. HER2 amplification ratios by fluorescence in situ hybridization and correlation with immunohistochemistry in a cohort of 6556 breast cancer tissues. Clin Breast Cancer (2004) 5(1):63-9. doi:10.3816/CBC.2004.n.011

55. Bachelot T, Romieu G, Campone M, Dieras V, Cropet C, Dalenc F, et al. Lapatinib plus capecitabine in patients with previously untreated brain metastases from HER2-positive metastatic breast cancer (LANDSCAPE): a single-group phase 2 study. Lancet Oncol (2013) 14(1):64-71. doi:10.1016/ S1470-2045(12)70432-1

56. Kennecke H, Yerushalmi R, Woods R, Cheang MC, Voduc D, Speers CH, et al. Metastatic behavior of breast cancer subtypes. JClin Oncol (2010) 28(20):3271-7. doi:10.1200/JCO.2009.25.9820

57. Venur VA, Leone JP. Targeted therapies for brain metastases from breast cancer. Int J Mol Sci (2016) 17(9):1543. doi:10.3390/ijms17091543

58. Niikura N, Liu J, Hayashi N, Mittendorf EA, Gong Y, Palla SL, et al. Loss of human epidermal growth factor receptor 2 (HER2) expression in metastatic sites of HER2-overexpressing primary breast tumors. J Clin Oncol (2012) 30(6):593-9. doi:10.1200/JCO.2010.33.8889

59. Stemmler HJ, Schmitt M, Willems A, Bernhard H, Harbeck N, Heinemann V. Ratio of trastuzumab levels in serum and cerebrospinal fluid is altered in HER2-positive breast cancer patients with brain metastases and impairment of blood-brain barrier. Anticancer Drugs (2007) 18(1):23-8. doi:10.1097/01. cad.0000236313.50833.ee

60. Swain SM, Baselga J, Kim SB, Ro J, Semiglazov V, Campone M, et al. Pertuzumab, trastuzumab, and docetaxel in HER2-positive metastatic breast cancer. N Engl J Med (2015) 372(8):724-34. doi:10.1056/NEJMoa1413513

61. Swain SM, Baselga J, Miles D, Im YH, Quah C, Lee LF, et al. Incidence of central nervous system metastases in patients with HER2-positive metastatic breast cancer treated with pertuzumab, trastuzumab, and docetaxel: results from the randomized phase III study CLEOPATRA. Ann Oncol (2014) 25(6):1116-21. doi:10.1093/annonc/mdu133

62. Taskar KS, Rudraraju V, Mittapalli RK, Samala R, Thorsheim HR, Lockman J, et al. Lapatinib distribution in HER2 overexpressing experimental brain metastases of breast cancer. Pharm Res (2012) 29(3):770-81. doi:10.1007/ s11095-011-0601-8

63. Lin NU, Carey LA, Liu MC, Younger J, Come SE, Ewend M, et al. Phase II trial of lapatinib for brain metastases in patients with human epidermal growth factor receptor 2-positive breast cancer. J Clin Oncol (2008) 26(12):1993-9. doi:10.1200/JCO.2007.12.3588

64. Lin NU, Dieras V, Paul D, Lossignol D, Christodoulou C, Stemmler HJ, et al. Multicenter phase II study of lapatinib in patients with brain metastases from HER2-positive breast cancer. Clin Cancer Res (2009) 15(4):1452-9. doi:10.1158/1078-0432.CCR-08-1080

65. Andre F, O’Regan R, Ozguroglu M, Toi M, Xu B, Jerusalem G, et al. Everolimus for women with trastuzumab-resistant, HER2-positive, advanced breast cancer (BOLERO-3): a randomised, double-blind, placebo-controlled phase 3 trial. Lancet Oncol (2014) 15(6):580-91. doi:10.1016/ S1470-2045(14)70138-X

66. Baselga J, Campone M, Piccart M, Burris HA III, Rugo HS, Sahmoud T, et al. Everolimus in postmenopausal hormone-receptor-positive advanced breast cancer. N Engl J Med (2012) 366(6):520-9. doi:10.1056/NEJMoa1109653

67. Turner NC, Ro J, Andre F, Loi S, Verma S, Iwata H, et al. Palbociclib in hormone-receptor-positive advanced breast cancer. N Engl J Med (2015) 373(3):209-19. doi:10.1056/NEJMoa1505270

68. Sahebjam S, Rhun EL, Kulanthaivel P, Turner PK, Klise S, Wang HT, et al. Assessment of concentrations of abemaciclib and its major active metabolites in plasma, CSF, and brain tumor tissue in patients with brain metastases secondary to hormone receptor positive (HR+) breast cancer. J Clin Oncol (2016) 34(15_suppl):526. doi:10.1200/JCO.2016.34.15_suppl.526

69. Dagogo-Jack I, Gill CM, Cahill DP, Santagata S, Brastianos PK. Treatment of brain metastases in the modern genomic era. Pharmacol Ther (2017) 170:64-72. doi:10.1016/j.pharmthera.2016.10.011

70. Fife KM, Colman MH, Stevens GN, Firth IC, Moon D, Shannon KF, et al. Determinants of outcome in melanoma patients with cerebral metastases. J Clin Oncol (2004) 22(7):1293-300. doi:10.1200/JCO.2004.08.140

71. Long GV, Menzies AM, Nagrial AM, Haydu LE, Hamilton AL, Mann GJ, et al. Prognostic and clinicopathologic associations of oncogenic BRAF in metastatic melanoma. JClin Oncol (2011) 29(10):1239-46. doi:10.1200/ JCO.2010.32.4327

72. Chapman PB, Hauschild A, Robert C, Haanen JB, Ascierto P, Larkin J, et al. Improved survival with vemurafenib in melanoma with BRAF V600E mutation. N Engl J Med (2011) 364(26):2507-16. doi:10.1056/NEJMoa1103782

73. Sosman JA, Kim KB, Schuchter L, Gonzalez R, Pavlick AC, Weber JS, et al. Survival in BRAF V600-mutant advanced melanoma treated with vemurafenib. N Engl J Med (2012) 366(8):707-14. doi:10.1056/NEJMoa1112302 
74. Long GV, Trefzer U, Davies MA, Kefford RF, Ascierto PA, Chapman PB, et al. Dabrafenib in patients with Val600Glu or Val600Lys BRAF-mutant melanoma metastatic to the brain (BREAK-MB): a multicentre, open-label, phase 2 trial. Lancet Oncol (2012) 13(11):1087-95. doi:10.1016/S1470-2045 (12)70431-X

75. Harding JJ, Catalanotti F, Munhoz RR, Cheng DT, Yaqubie A, Kelly N, et al. A retrospective evaluation of vemurafenib as treatment for BRAF-mutant melanoma brain metastases. Oncologist (2015) 20(7):789-97. doi:10.1634/ theoncologist.2014-0012

76. Long GV, Stroyakovskiy D, Gogas H, Levchenko E, de Braud F, Larkin J, et al. Combined BRAF and MEK inhibition versus BRAF inhibition alone in melanoma. N Engl J Med (2014) 371(20):1877-88. doi:10.1056/ NEJMoa1406037

77. Long GV, Stroyakovskiy D, Gogas H, Levchenko E, de Braud F, Larkin J, et al. Dabrafenib and trametinib versus dabrafenib and placebo for Val600 BRAF-mutant melanoma: a multicentre, double-blind, phase 3 randomised controlled trial. Lancet (2015) 386(9992):444-51. doi:10.1016/ S0140-6736(15)60898-4

78. Robert C, Karaszewska B, Schachter J, Rutkowski P, Mackiewicz A, Stroiakovski D, et al. Improved overall survival in melanoma with combined dabrafenib and trametinib. N Engl J Med (2015) 372(1):30-9. doi:10.1056/ NEJMoa1412690

79. Meier FE, Niessner H, Schmitz J, Schmid A, Calaminus C, Pichler B, et al. The PI3K inhibitor BKM120 has potent antitumor activity in melanoma brain metastases in vitro and in vivo. J Clin Oncol (2013) 31(15_suppl):e20050. doi:10.1200/jco.2013.31.15_suppl.e20050

80. Wolchok JD, Saenger Y. The mechanism of anti-CTLA-4 activity and the negative regulation of T-cell activation. Oncologist (2008) 13(Suppl 4):2-9. doi:10.1634/theoncologist.13-S4-2

81. Hodi FS, O’Day SJ, McDermott DF, Weber RW, Sosman JA, Haanen JB, et al. Improved survival with ipilimumab in patients with metastatic melanoma. $N$ Engl J Med (2010) 363(8):711-23. doi:10.1056/NEJMoa1003466

82. Margolin K, Ernstoff MS, Hamid O, Lawrence D, McDermott D, Puzanov I, et al. Ipilimumab in patients with melanoma and brain metastases: an open-label, phase 2 trial. Lancet Oncol (2012) 13(5):459-65. doi:10.1016/ S1470-2045(12)70090-6

83. Robert C, Ribas A, Wolchok JD, Hodi FS, Hamid O, Kefford R, et al. Anti-programmed-death-receptor-1 treatment with pembrolizumab in ipilimumab-refractory advanced melanoma: a randomised dose-comparison cohort of a phase 1 trial. Lancet (2014) 384(9948):1109-17. doi:10.1016/ S0140-6736(14)60958-2

84. Robert C, Schachter J, Long GV, Arance A, Grob JJ, Mortier L, et al. Pembrolizumab versus ipilimumab in advanced melanoma. $N$ Engl J Med (2015) 372(26):2521-32. doi:10.1056/NEJMoa1503093

85. Larkin J, Chiarion-Sileni V, Gonzalez R, Grob JJ, Cowey CL, Lao CD, et al. Combined nivolumab and ipilimumab or monotherapy in untreated melanoma. N Engl JMed (2015) 373(1):23-34. doi:10.1056/NEJMoa 1504030

86. Christensen TD, Spindler KL, Palshof JA, Nielsen DL. Systematic review: brain metastases from colorectal cancer - incidence and patient characteristics. BMC Cancer (2016) 16:260. doi:10.1186/s12885-016-2290-5

87. Yaeger R, Cowell E, Chou JF, Gewirtz AN, Borsu L, Vakiani E, et al. RAS mutations affect pattern of metastatic spread and increase propensity for brain metastasis in colorectal cancer. Cancer (2015) 121(8):1195-203. doi:10.1002/cncr.29196

88. Tran B, Kopetz S, Tie J, Gibbs P, Jiang ZQ, Lieu CH, et al. Impact of BRAF mutation and microsatellite instability on the pattern of metastatic spread and prognosis in metastatic colorectal cancer. Cancer (2011) 117(20):4623-32. doi: $10.1002 /$ cncr.26086
89. Tie J, Lipton L, Desai J, Gibbs P, Jorissen RN, Christie M, et al. KRAS mutation is associated with lung metastasis in patients with curatively resected colorectal cancer. Clin Cancer Res (2011) 17(5):1122-30. doi:10.1158/10780432.CCR-10-1720

90. Bianchi M, Sun M, Jeldres C, Shariat SF, Trinh QD, Briganti A, et al. Distribution of metastatic sites in renal cell carcinoma: a population-based analysis. Ann Oncol (2012) 23(4):973-80. doi:10.1093/annonc/mdr362

91. Chang EL, Selek U, Hassenbusch SJ III, Maor MH, Allen PK, Mahajan A, et al. Outcome variation among "radioresistant" brain metastases treated with stereotactic radiosurgery. Neurosurgery (2005) 56(5):936-45; discussion-45. doi:10.1227/01.NEU.0000158324.20757.AC

92. Beck J, Procopio G, Bajetta E, Keilholz U, Negrier S, Szczylik C, et al. Final results of the European Advanced Renal Cell Carcinoma Sorafenib (EU-ARCCS) expanded-access study: a large open-label study in diverse community settings. Ann Oncol (2011) 22(8):1812-23. doi:10.1093/annonc/mdq651

93. Jager D, Ma JH, Mardiak J, Ye DW, Korbenfeld E, Zemanova M, et al. Sorafenib treatment of advanced renal cell carcinoma patients in daily practice: the large international PREDICT study. Clin Genitourin Cancer (2015) 13(2):156-64.e1. doi:10.1016/j.clgc.2014.07.007

94. Verma J, Jonasch E, Allen PK, Weinberg JS, Tannir N, Chang EL, et al. The impact of tyrosine kinase inhibitors on the multimodality treatment of brain metastases from renal cell carcinoma. Am J Clin Oncol (2013) 36(6):620-4. doi:10.1097/COC.0b013e31825d59db

95. Gore ME, Szczylik C, Porta C, Bracarda S, Bjarnason GA, Oudard S, et al. Final results from the large sunitinib global expanded-access trial in metastatic renal cell carcinoma. Br J Cancer (2015) 113(1):12-9. doi:10.1038/ bjc. 2015.196

96. Motzer RJ, Escudier B, McDermott DF, George S, Hammers HJ, Srinivas S, et al. Nivolumab versus everolimus in advanced renal-cell carcinoma. $N$ Engl J Med (2015) 373(19):1803-13. doi:10.1056/NEJMoa1510665

97. Hardy JR, Harvey VJ. Cerebral metastases in patients with ovarian cancer treated with chemotherapy. Gynecol Oncol (1989) 33(3):296-300. doi:10.1016/0090-8258(89)90515-5

98. Balendran S, Liebmann-Reindl S, Berghoff AS, Reischer T, Popitsch N, Geier CB, et al. Next-generation sequencing-based genomic profiling of brain metastases of primary ovarian cancer identifies high number of BRCA-mutations. J Neurooncol (2017) 133(3):469-76. doi:10.1007/ s11060-017-2459-Z

99. Mateo J, Boysen G, Barbieri CE, Bryant HE, Castro E, Nelson PS, et al. DNA repair in prostate cancer: biology and clinical implications. Eur Urol (2017) 71(3):417-25. doi:10.1016/j.eururo.2016.08.037

100. Forster MD, Dedes KJ, Sandhu S, Frentzas S, Kristeleit R, Ashworth A, et al. Treatment with olaparib in a patient with PTEN-deficient endometrioid endometrial cancer. Nat Rev Clin Oncol (2011) 8(5):302-6. doi:10.1038/ nrclinonc. 2011.42

101. Su JM, Thompson P, Adesina A, Li XN, Kilburn L, Onar-Thomas A, et al. A phase I trial of veliparib (ABT-888) and temozolomide in children with recurrent CNS tumors: a pediatric brain tumor consortium report. Neuro Oncol (2014) 16(12):1661-8. doi:10.1093/neuonc/nou103

Conflict of Interest Statement: PB has consulted for Merck, Lilly, Genentech, and Angiochem. $\mathrm{CH}$ declares no conflict of interest.

Copyright (c) 2017 Han and Brastianos. This is an open-access article distributed under the terms of the Creative Commons Attribution License (CC BY). The use, distribution or reproduction in other forums is permitted, provided the original author(s) or licensor are credited and that the original publication in this journal is cited, in accordance with accepted academic practice. No use, distribution or reproduction is permitted which does not comply with these terms. 